Supplement of Biogeosciences, 15, 4163-4180, 2018

https://doi.org/10.5194/bg-15-4163-2018-supplement

(C) Author(s) 2018. This work is distributed under

the Creative Commons Attribution 4.0 License.

(c) (1)

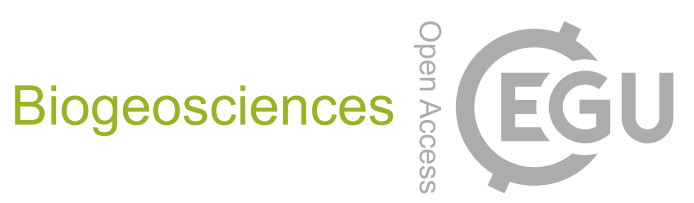

Supplement of

\title{
Long-term response of oceanic carbon uptake to global warming via phys- ical and biological pumps
}

Akitomo Yamamoto et al.

Correspondence to: Akitomo Yamamoto (akitomo@jamstec.go.jp)

The copyright of individual parts of the supplement might differ from the CC BY 4.0 License. 


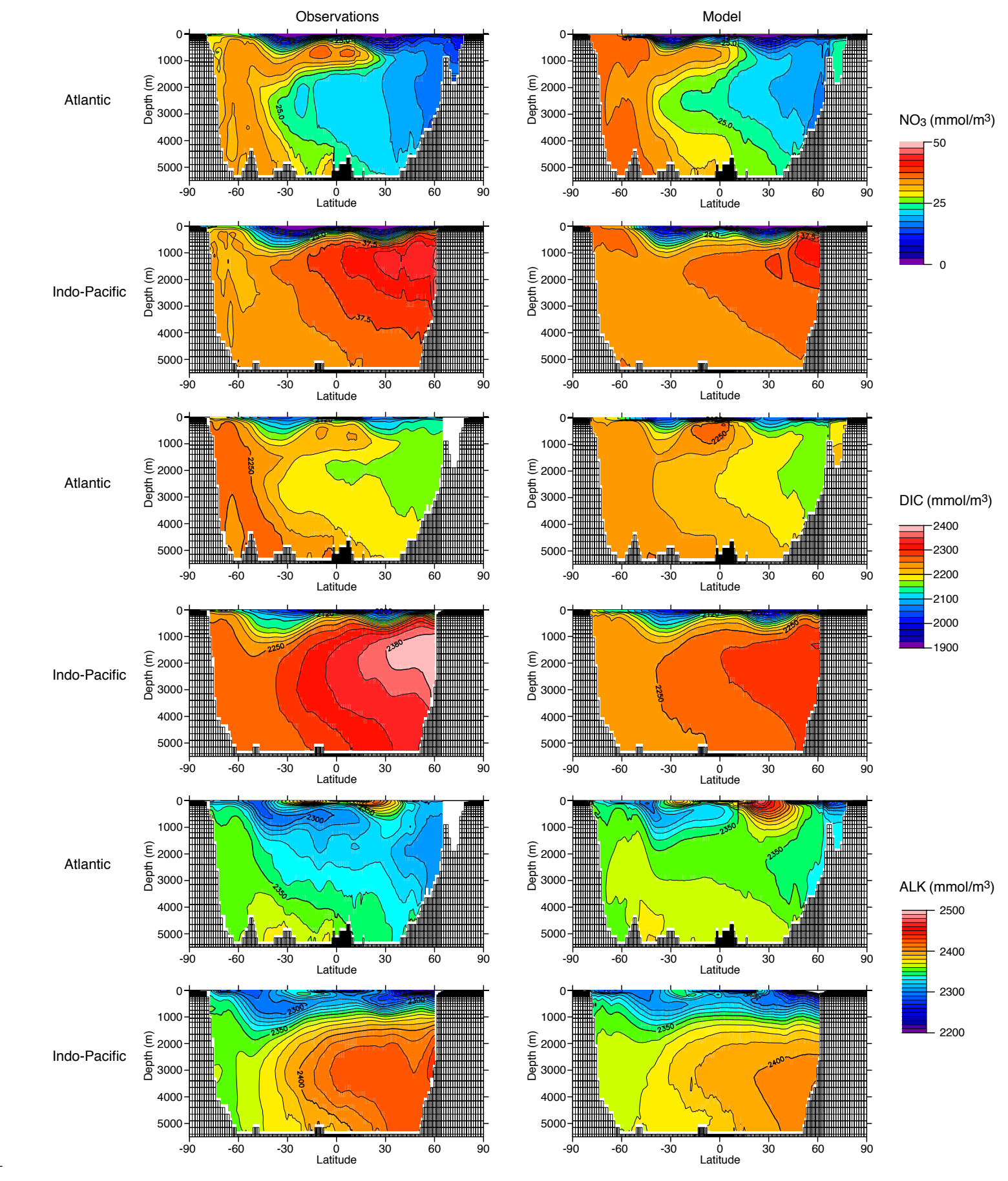

2 Figure S1. Zonal distribution of nitrate $\left(\mathrm{NO}_{3}\right)$, dissolved inorganic carbon (DIC) and

3 alkalinity (ALK) for the Atlantic and Indo-Pacific Ocean in the observation (left) and

4 model (right). 


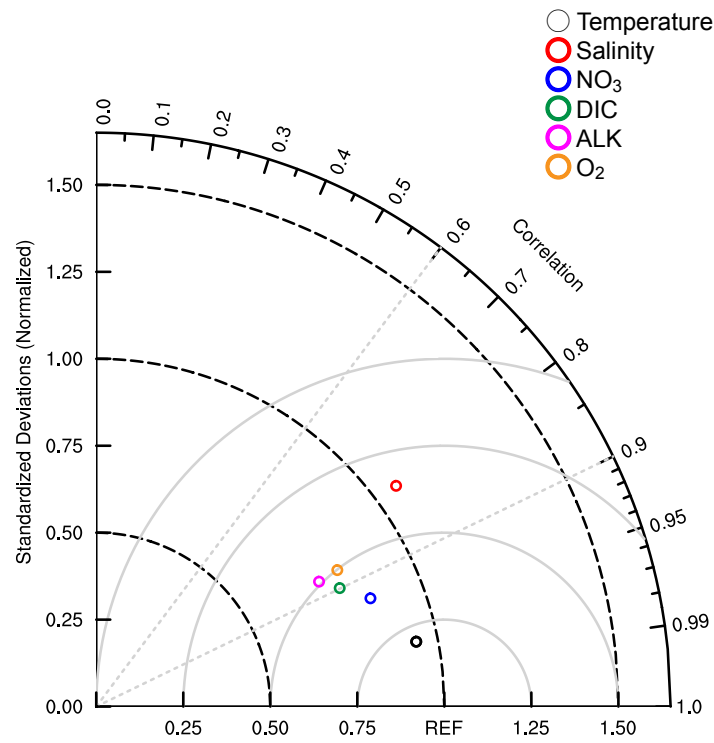

7 Figure S2. Physical and biogeochemical variables in the pre-industrial experiments are

8 compared with observational datasets in a Taylor diagram (Taylor, 2001).
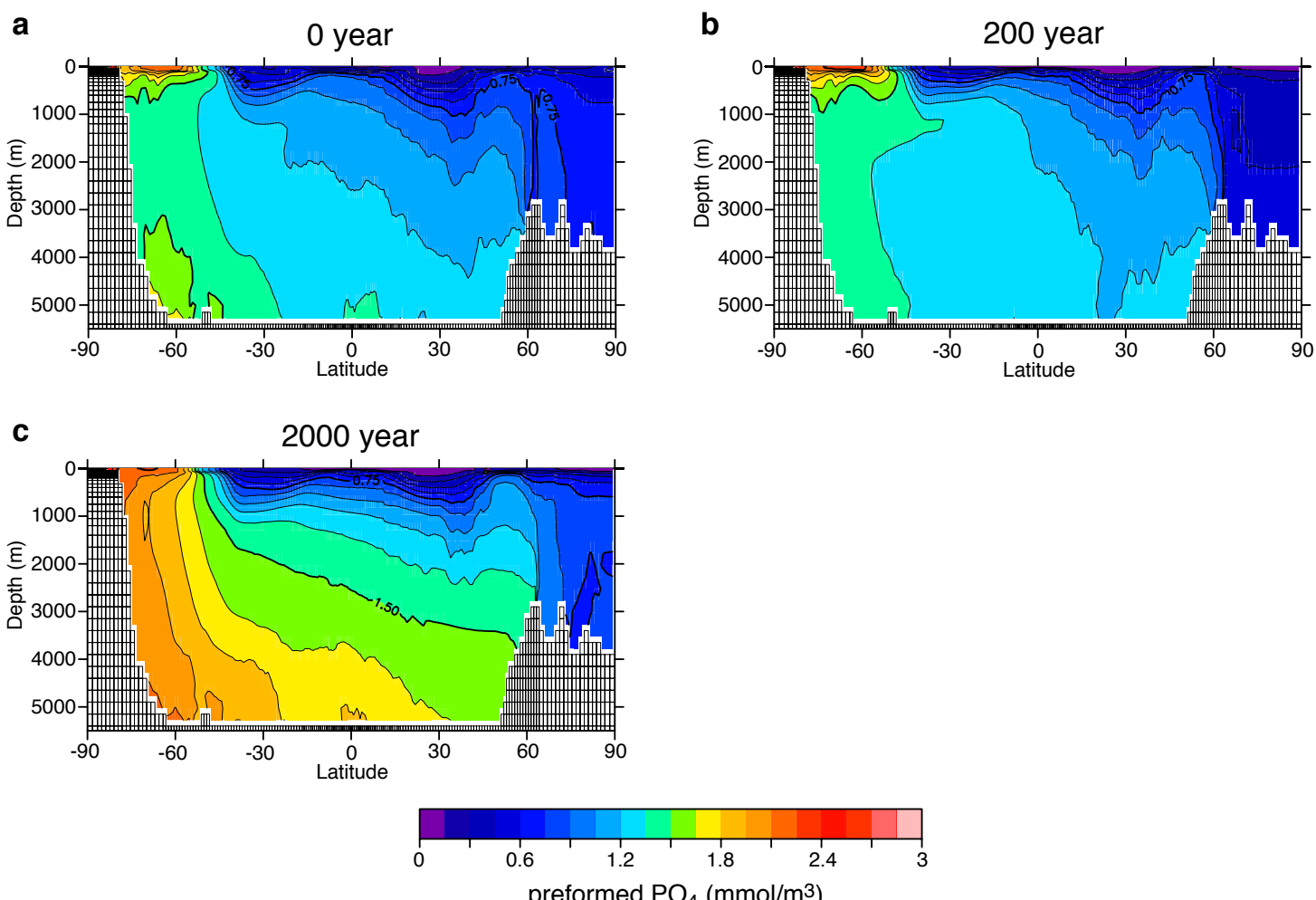

preformed $\mathrm{PO}_{4}\left(\mathrm{mmol} / \mathrm{m}^{3}\right)$

11 Figure S3. Zonal mean distribution of preformed $\mathrm{PO}_{4}$ for (a) 0 years, (b) 200 years and 

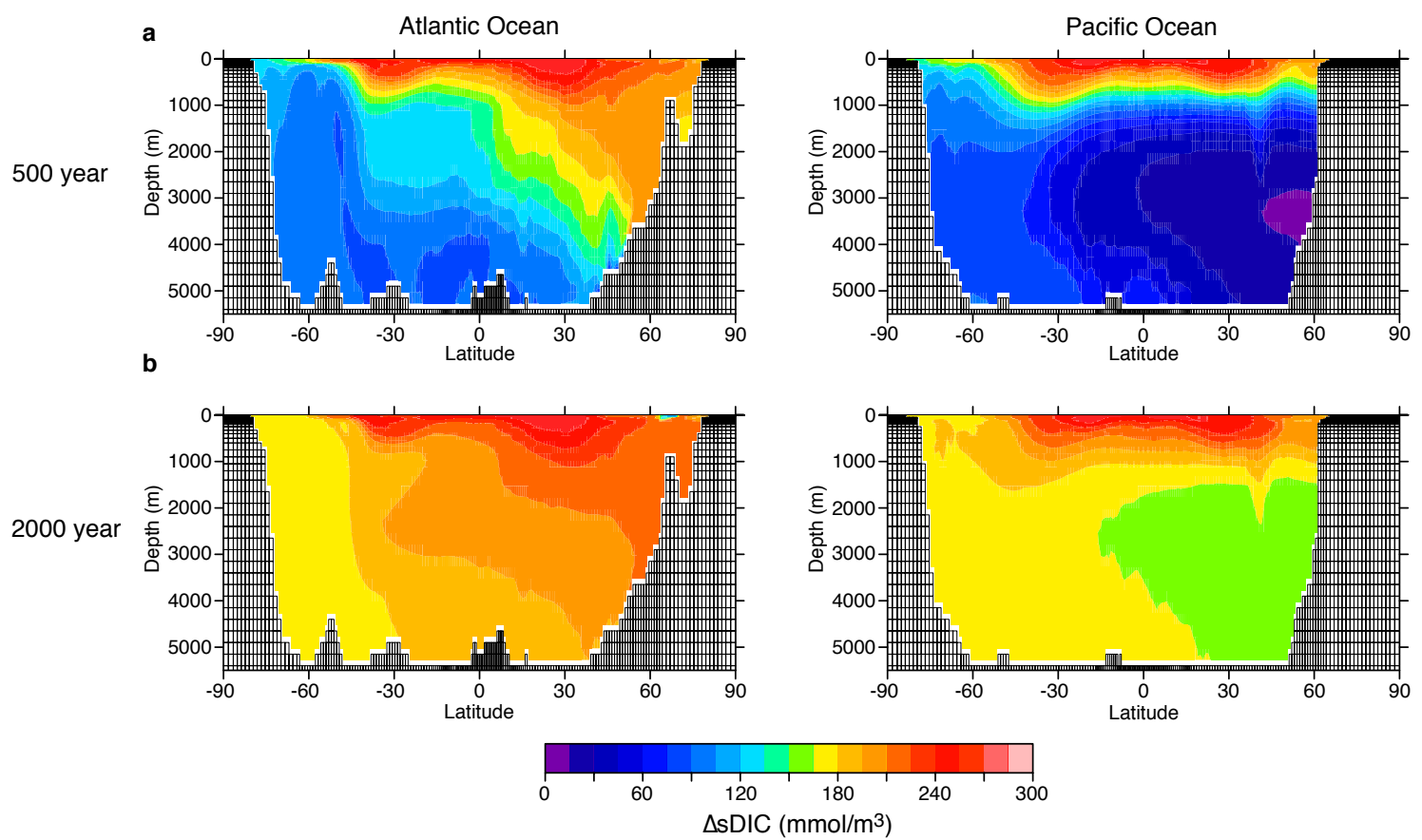

15 Figure S4. Zonal mean distribution of changes in the salinity-normalized DIC for (a)

16500 years and (b) 2000 years in the constant-climate run (CTL_bio). The left and right

17 panels show the Atlantic and Indo-Pacific Oceans, respectively.

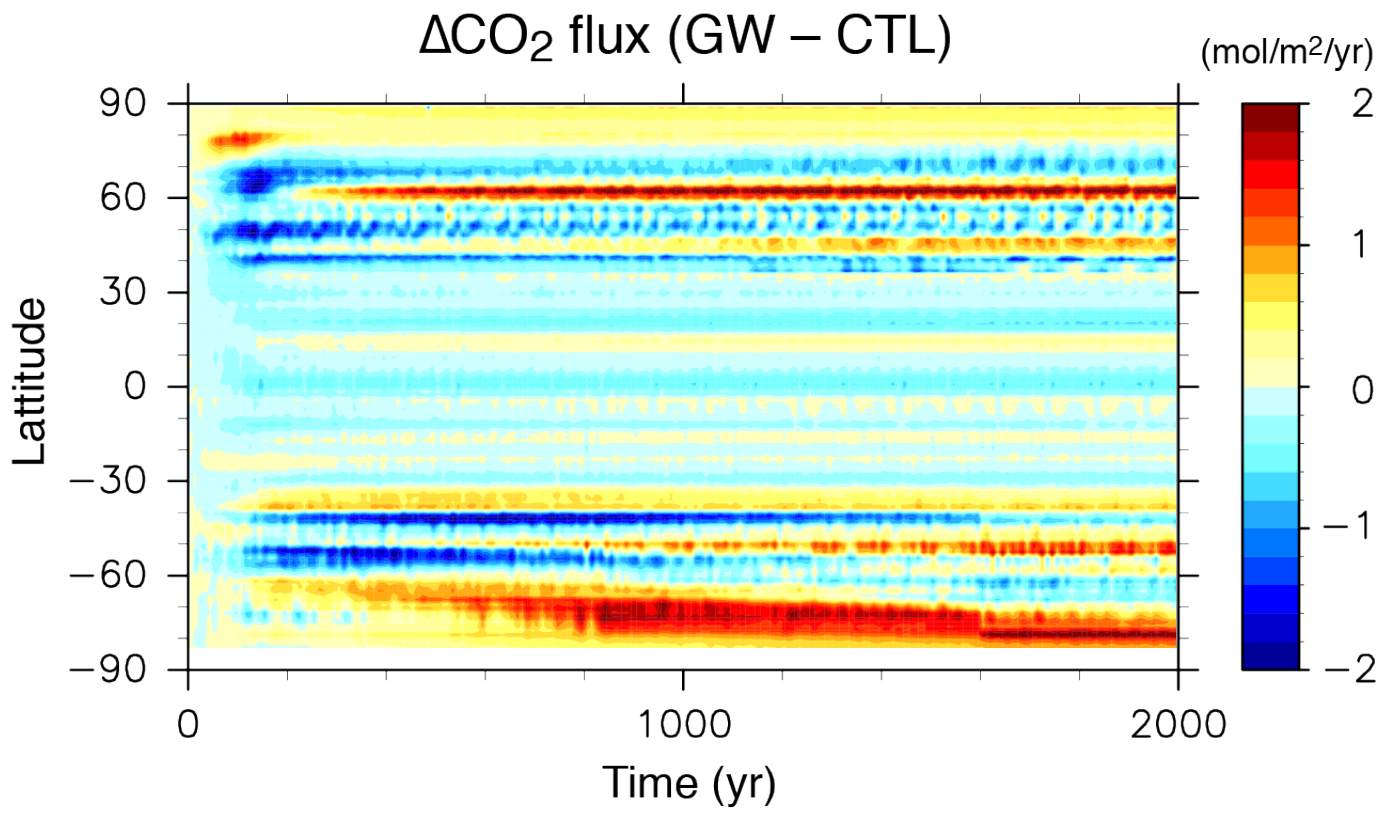

19 Figure S5. Hovmöller diagram of the $\mathrm{CO}_{2}$ uptake anomaly of $\mathrm{GW}$ bio-CTL_bio. 